\title{
Coping with Complex Real-World Problems: Strategies for Developing the Competency of Transdisciplinary Collaboration
}

\author{
Gitta Domik $^{1}$ and Gerhard Fischer ${ }^{2}$ \\ ${ }^{1}$ University of Paderborn, Warburgerstrasse 100, D-33098 Paderborn, Germany \\ domik@uni-paderborn.de \\ ${ }^{2}$ University of Colorado at Boulder, Boulder, CO. 80301-0430, USA \\ gerhardecolorado.edu
}

\begin{abstract}
Real world problems are complex and therefore between and beyond disciplines. To solve them requires expertise across several disciplines. This paper argues that we need to teach students transdisciplinary collaboration as a competency demanded in future work places. We describe two learning strategies, "breadth-first" and "Long Tail", to help develop these competencies in graduate students. An implementation of these strategies in a computer science course with 48 graduate students from various disciplines is described. Finally, implications and future opportunities of our approach are discussed.
\end{abstract}

Keywords: Transdisciplinary Collaboration, Lifelong Learning, $21^{\text {st }}$ century competencies.

\section{Transdisciplinary Collaboration: A Necessity, Not a Luxury}

Education in Computer Science (CS) is experiencing a period of profound transformation. Phenomena such as globalization [1], increasing trends to outsource high-level cognitive tasks [2], and the need to participate effectively in addressing complex real world problems cutting across disciplines are creating fundamentally new challenges. Requirements increase for students to enter work environments requiring collaboration with experts from multiple fields, pursue several career paths addressing different problems, and to interact and work with people of diverse backgrounds including those from outside academe. Such changes create new educational demands: students need to be educated for a diverse, technical, problem-oriented world that does not yet exist, which makes it imperative that they become self-directed, lifelong learners who can thrive and participate in collaborative environments with ever-changing disciplinary boundaries.

Real world problems are complex, they cannot be framed and solved by any single person, and they often cut across different established disciplines requiring expertise in a wide range of areas. In preparing students to live and work in the "knowledge age", one cannot predict or learn in school what one may need to know during a lifetime of work [3]. Coverage is impossible and obsolescence is guaranteed. These 
requirements have led us to articulate our credo for a lifelong learning perspective on education [4]:

"If the world of working and living relies on collaboration, creativity, definition and framing of complex problems and if it requires dealing with uncertainty, change, and intelligence that is distributed across cultures, disciplines, and tools - then education should foster transdisciplinary competencies and mindsets that prepare students for having meaningful and productive lives in such a world."

Nevertheless, contemporary higher education is primarily characterized by receiving knowledge out of one single department (usually synonymous with one single discipline), therefore forming specialists with depth in unidisciplinary knowledge and discipline-dependent characteristics ("stereotypes"). We support "tribal behaviour" in our departments, creating "artists" and "computer scientists" and "geologists", each group harmonizing in knowledge, preferred color schemes and language. How can we continuously support quality and depth in education but additionally coach collaboration with other "tribes"? The objective of this paper is to present solutions for this problem that are aimed at having students practice meaningful collaboration with other disciplines.

In order to do so, we define and differentiate between multi-, inter- and transdisciplinary approaches to science and education and describe transdisciplinary collaboration as the soft skill, or competency, that is necessary to participate in inter- and transdisciplinary activities. Derived from a lifelong learning perspective, we postulate that being prepared for engaging in transdisciplinary collaboration at the work place, learners need to have opportunities to engage and experience transdisciplinary collaboration during education. Not to do so would postulate that graduates will undergo the "big switch" in professional life, transforming from being mostly consumers of educational material within their own discipline to become self-directed, responsible and socially competent learners in collaborative and diverse environments. We assess the pros and cons of collaborative education and postulate two strategies, breadth-first and Long Tail, that aid in the learning process. An implementation of theses strategies in a standard CS course with 48 graduate students is described. Furthermore, we discuss implications and future opportunities of our approach.

\section{Transdisciplinarity and Transdisciplinary Collaboration}

Transdisciplinary collaboration is a group process between individuals trained in different disciplines, e.g. astrophysicists, computer scientists, biologists, designers. Educators variously use the terms multidisciplinarity, interdisciplinarity, and transdisciplinarity to describe collaborations, often without clearly distinguishing among them, though these terms are well defined and distinguished by e.g. Klein [5], Rosenfield [6] and Nicolescu [7]. In short,

multidisciplinarity means that several disciplines are being involved either in a sequential or juxtaposed mode;

interdisciplinarity implies integration or blending of knowledge from different disciplines,

transdisciplinarity places the highest demand, namely forming new knowledge from available unidisciplinary awareness. 
In a practical view of multi/inter/transdisciplinarity in education we use the example of teaching "Color" (standard lecture in a computer graphics course) to a group of students from multiple disciplines (e.g. students of physics, biology, computer science, and design). An educator from each of the four involved departments may give a talk on "Color" from their perspective. It is easy to visualize the different approaches each educator will take: a physicist might start with Newton's experiments; a biologist with the structure of the human eye; the computer scientist with the RGB color model; and the design expert maybe with the notion of "color and aesthetics". In a multidisciplinary approach, students are left with this input, and it is up to them to find the overlap and "in between" in these approaches on their own. In an interdisciplinary approach, each educator will overlap with content of other talks, and interdisciplinary student teams might form to work on an appropriate assignment together. Most probably these teams will split up the tasks according to their abilities but present a final, common solution for the assignment. In a transdisciplinary course, the interdisciplinary approach will be expanded by discussing the commonalities and differences of approaches. Educators together with students will attempt to create additional perspectives on the theme that were not inherent in each of the approaches. In transdisciplinary processes participants will learn from each other, and a collaborative knowledge construction can take place that will be expressed in entirely new chapters expressing the thus gained knowledge [8].

The step from multidisciplinarity (separate knowledge) to interdisciplinarity and transdisciplinarity (overlapping knowledge and knowledge beyond disciplines) is powerful. But at what educational level will students be mature enough to blend knowledge or to form new knowledge? Derry and Fischer [4] specifically argue for a transdisciplinary education at graduate level. Rosenfield [6] also places transdisciplinary training at the early graduate level, because a solid grounding in their own discipline, respect for the contributions that other disciplines can make, and the sensitivity to cooperative endeavour is a prerequisite to perform transdisciplinary research.

\subsection{Transdisciplinary Collaboration}

How can a team of scientists achieve a collaboration qualified to support transdisciplinarity? Stokols [9] observes in his scientific collaborations the following factors supporting transdisciplinary collaboration:

- members`strong commitment to achieving transdisciplinary goals and outcomes

- interpersonal skills of team leaders

- $\quad$ history of prior collaboration among team members

- $\quad$ spatial proximity of team members`offices and laboratories

- $\quad$ schedule frequent face-to-face meetings for brain-storming of ideas

- establish electronic linkages among participants

- foster institutional supports for transdisciplinary collaboration

And the following factors constraining transdisciplinary collaboration:

- substantial time required to establish common conceptual ground and informal social ties 
- unrealistic expectations and ambiguity about shared goals and products

- conflicts among alternative disciplinary views of science

- bureaucratic impediments to cross-departmental collaboration.

While Stokols' research is on scientific collaboration (to improve understanding of nicotine addiction), these indicators now need to be understood in an educational setting. Table 1 transfers educational relevant indicators to a constructive condition in education.

Table 1. Demands for Transdisciplinary Collaboration in Science Transferred to Education

\begin{tabular}{|l|l|}
\hline \multicolumn{1}{|c|}{ Demand by Stokols [9] } & \multicolumn{1}{c|}{ How educators can be of support: } \\
\hline $\begin{array}{l}\text { support members`strong commitment to } \\
\text { achieving transdisciplinary goals and } \\
\text { outcomes }\end{array}$ & $\begin{array}{l}\text { support students in } \\
\text { - finding unique topics they feel } \\
\text { passionate about; } \\
\text { team building process }\end{array}$ \\
\hline $\begin{array}{l}\text { reduce time required to establish common } \\
\text { conceptual ground and informal social ties }\end{array}$ & $\begin{array}{l}\text { establish common language and help } \\
\text { establish social ties }\end{array}$ \\
\hline $\begin{array}{l}\text { schedule frequent face-to-face meetings } \\
\text { for brain-storming of ideas }\end{array}$ & $\begin{array}{l}\text { encourage and enforce face-to-face } \\
\text { meetings; give help with structure of } \\
\text { these meetings }\end{array}$ \\
\hline $\begin{array}{l}\text { establish electronic linkages among } \\
\text { participants }\end{array}$ & $\begin{array}{l}\text { encourage the use of free electronic } \\
\text { linkages, e.g, Wikis, Skype, or ICQ } \\
\text { additionally to Email }\end{array}$ \\
\hline $\begin{array}{l}\text { constrain unrealistic expectations and } \\
\text { ambiguity about shared goals and products; } \\
\text { constrain conflicts among alternative } \\
\text { disciplinary views of science }\end{array}$ & $\begin{array}{l}\text { participate in selected face-to-face } \\
\text { meetings to constrain "tribal behav- } \\
\text { iour" through own interpersonal and } \\
\text { interdisciplinary skills }\end{array}$ \\
\hline
\end{tabular}

From Table 1 we can derive two issues that are paramount:

- students need to find a common ground for their communication;

- students need projects that they feel committed to out of personal interest.

Once these concerns are solved, the other issues (e.g. enforcing meaningful group meetings and electronic linkage) will be easier to solve. Solutions are proposed in the next chapters through breadth-first and Long Tail strategies.

\section{Developing the Competency of Transdisciplinary Collaboration}

"The CS curriculum is no interdisciplinary playground": Nowhere in the CS computing curricula [10] do we define "soft skills" as a core or optional topic. Nevertheless, computer science students must and will learn essential soft skills during their years at the university: e.g. communication skills (in speech, in writing, visual), or working in teams. "[Soft] skills should not be seen as separate but should instead be fully incorporated into the computer science curriculum and its requirements" as requested in [10]: Educators teach communication skills while giving a seminar or advising a 
bachelor or master thesis; or use software projects to teach team work in software engineering.

We have to aim at teaching transdiciplinary collaboration in a similar way: focusing on the content of our CS curriculum but at the same time preparing students for that important competency. While a seminar is better than a lecture course in teaching the competency of oral presentation, we can identify in [10] areas of knowledge that will hold that promise for TD collaboration, e.g. the area of Graphics and Visual Computing, where courses on visualization, augmented reality, animation, or (more recently) game development, deepen the knowledge of graphics architecture or rendering algorithms. These knowledge units are already multidisciplinary by nature and gain by admitting students from other disciplines.

"Will we attract students from other disciplines?" Technical competency is ranked high in the job market, so students of other disciplines are showing sufficient interest in joining computer science courses if the prerequisites are manageable [11]. While an electrical engineering student might be interested in rendering and OpenGL programming to better utilize her knowledge on signal processing, a media design student might have interest in Flash scripting or a student of journalism to set up a Wiki.

"But it will take forever to teach programming skills to non-technical students": Acquiring skills in a successful course of mixed disciplines (at the graduate level) will be a suitable balancing of breadth and depth of participating students. In a visualization project for computer science and physics students using air flow data, computer science students will gain depth in developing and implementing real-time flow visualization algorithms, physics student will only acquire breadth knowledge in that area. With a joint lecturer of the physics department involved, computer science students can acquire breadth knowledge of modelling air flows while physics students can deepen their previous theoretical knowledge in fluid dynamics. There should be no need to take Physics 101 for CS students, or for Physics students to take the CS introductory course to $\mathrm{C}++$, to work jointly on projects.

Sometimes CS educators complain about how long it takes to teach non-technical students the skills of programming before "real" work on joint projects can start, when they should concentrate on developing a common ground for all students so they could work together on a solution, each grounded in the skills of their own discipline and extending into the other discipline only to build necessary overlaps.

\subsection{Breadth-First: Finding a Common Language between Disciplines}

The breadth-first approach was suggested as one of three possible approaches to teach computer science by the CS computing curricula 2001 [10]. It can also be used to teach individual courses or topics. The idea of breadth-first is to start with a holistic view of each topic to teach (breadth) and undermine it with an application; then use depth to the level the students are ready for. The first part (breadth) provides overall understanding of the topic on an entry level. The application should give extra motivation to learn more about this topic. The second part (depth) will built up through sophisticated layers and is designed for a specific discipline. If a topic is prepared breadth-first, then the breadth part of the course can be simultaneously taught to students of various disciplines. Advantages for a breadth-first approach are: 
- CS students get a holistic view of a topic before they learn about more complicated details;

- CS students can then move on to any depth-level;

- students of other disciplines learn of the importance of a topic through the goal of the application;

- students of different backgrounds can be taught together at the breadth-level;

- all students are being taught the same "language" to describe a topic;

- application oriented approaches are motivational to both men and women.

"SIMBA - Computer Pictures" is an educational tool to teach computer generated color and computer generated visualization via the breadth-first method [12]. Topics at the first level are comprehensible to students of all disciplines; each further level increases the difficulty in acquiring revealed knowledge. Thus found depth is appropriate for computer science students.

The result of this approach is that breadth-first leaves students of different disciplines with a common language that they can use to discuss goals and strategies for joint visualization projects. This common language is essentially the most important ingredient for transdisciplinary collaboration, because without it the door stays open for misunderstandings, unrealistic expectations and ambiguity about shared goals.

\subsection{Long Tail: Passion-Based and Self-motivated Learning}

The concept of the Long Tail (as developed in business environments) [13] postulates that our culture and economy are increasingly shifting away from a focus on a relatively small number of products and markets at the head of the popularity curve toward a huge number of niches in the tail. Research at the Center for LifeLong Learning \& Design (L3D) reinterprets and explores the Long Tail business environments for transforming learning and education $[14,15]$ as seen in Table 2.

Table 2. Long Tail Concepts in Business and in Learning and Education

\begin{tabular}{|l|l|}
\hline Web-Based Businesses & Learning and Education \\
\hline unlimited shelf-space & unlimited knowledge \\
\hline megahits (head) & core curriculum (head) \\
\hline niche markets (tail) & passion for unique topics (tail) \\
\hline hybrid model of distribution [16] & hybrid model of learning and discovery \\
\hline $\begin{array}{l}\text { many interesting books, movies, songs } \\
\text { will not enter the traditional marketplace }\end{array}$ & $\begin{array}{l}\text { many interesting topics and ideas will } \\
\text { not be taught in traditional learning } \\
\text { environments }\end{array}$ \\
\hline
\end{tabular}

Assessing passion-based, self-motivated learning based on Web 2.0/Long Tail requires fundamentally different assessment approaches compared to what standard educational testing can offer [17]. L3D is currently researching to understand the benefits to the kinds of education that this approach can afford, such as the ability of learners to pursue those topics of interest to them and to take responsibility for their 
own education (examples of courses can be found at http://13d.cs.colorado.edu/ gerhard/courses/). By focusing on the tail of the Long Tail, we will not ignore the head but we will create a synergy between the two. Interest driven activities are boundary crossing: they move across settings of home, school, work, community, and online. In the context to enhance the competency of transdisciplinary collaboration and education this means that the Long Tail approach will be grounded in the following assumptions [18]:

- The activities of the head are the course topics that computer science students will improve their depth in, and students of other disciplines will learn to understand on a breadth level. The motivation for participation is mostly determined by extrinsic motivation (e.g. for credits; to improve job market value).

- The activities of the tail (the major contribution of Long Tail learning) should be focused on interest and passion allowing learners of all disciplines to pursue personally meaningful problems. The motivation for participation is mostly determined by intrinsic motivation. Learning and discovery are facilitated by passion-based participation on niche topics.

In the following chapter we will show the use of breadth-first and Long Tail in a one semester graduate computer science course with 48 participating students representing three different groups of disciplines: computer science, business information systems and non-technical students (e.g. from media science or German language department).

\section{Using Long Tail and Breadth-First Strategies in Graduate Computer Science Course}

Setting of the course: The University of Paderborn has 14.000 students and is divided into five faculties. The course "Data and Information Visualization" is offered in the CS graduate program as part of a computer graphics module. For the Summer Term 2009 it was opened to graduate students of all disciplines and thus gained 48 participants from three different faculties: 29 CS students (Faculty of Computer Science, Mathematics and Electrical Engineering), 14 business information systems students (Faculty of Business Administration and Economics), 5 non-technical students (media science students and literature students - all from the Faculty of Arts and Humanities). The visualization course included 90 minutes of lecture and 45 minutes of lab time per week over a period of 15 weeks. Students received 4 ECTS $^{1}$ for the course, which translates to an expected effort of 100-120 hours of work on the student's side. In the lectures students learn methods and techniques to visualize information and data in an expressive and effective way. Lab time is being used to practice concepts and techniques. Starting in week 4, students worked on interdisciplinary projects of their choice in teams of their choice (with the restriction that each team had to hold a sufficient disciplinary mix).

Helping students to find a Common Ground: Computer-generated visualization (including visualization of data derived from scientific measurements or scientific computing, or collected by humans or machines) holds multitudes of examples useful

\footnotetext{
${ }^{1}$ European Credit Transfer and Accumulation System.
} 
for teaching. Most of these are multidisciplinary, owing the context to an application outside CS, while the interactive graphics is clearly of interest to our CS students. Additionally, perception, design, and other areas of disciplines outside CS, play an important role in computer-generated visualization. The core topics to teach computer-generated visualization are [19]: definitions; data; user and tasks; mapping from data parameters to visual attributes; representation techniques; interaction issues; concepts of the visualization process; and systems and tools. These eight core topics constitute the head of the knowledge to be conveyed in a visualization course. Using the educational tool "SIMBA - Computer Pictures" (section 3.2) these core topics were taught with a breadth-first strategy during lectures. Of the typically four levels for each core topic (increasing level means increasing depth for computer science students) level one and two were presented in class, suitable for all disciplines. This strategy helps both to teach the content of visualization to all students, but also to remove misunderstandings in the communication by providing a common language: e.g. while an "effective" animation might mean "real-time" for a computer scientist it might mean "aesthetic" to a student of the arts department. However, "effectiveness" for visualization has been well defined by [20] to mean that one visualization is more effective than another visualization if the information conveyed by one visualization is more readily perceived than the information in the other visualization.

One major obstacle in interdisciplinary courses is that of building project teams over the first weeks of a course, while students of different disciplines are still unfamiliar with each other. So additionally to providing a common language, the goal was to also facilitate social ties to help in the team building process. While the use of social networks to get to know each other seems a good idea, the practical side of it makes it useless for a one semester course: Once each of the 48 students have become "friends" on a social network, they will slowly get to know each other. This process develops slowly for large groups and is hard to hurry. Alternatively, the solution in this course was an early lab assignment, requesting to fill out a "private profile". If a question appeared too private, students were allowed to skip it. It was also made clear that not handing in this assignment would not lead to a lesser grade. The form contained information such as "my abilities for the project group", "degree program of student", "former high school", "memberships in clubs or associations", or" favourite films/books". Students were also asked for 1-2 personal pictures and their first name. The resulting document was made available on the web (password secured). Every one of 48 students submitted this "private profile".

Helping Students in finding topics they feel passionate about: Starting in the first lecture, each core topic and concept was enforced by visualization examples in application contexts. This aided both the breath-first approach in teaching as well as the later search for unique project topics for students. Examples given included: visualization of large, multivariate environmental data; software visualization (e.g. algorithm animation, visualization of large code parts), augmented reality to support surgery; visualization of large information spaces, such as demographic data, etc. In each of these cases visualizations aid in the interpretation of complex data for a specific context (often outside CS), but are only possible through special visualization techniques: e.g. animation, flow visualization, GPU-based volume rendering, etc. These visualizations constituted the tail of visualization knowledge and offered context for other disciplines but also depth knowledge in visualization for computer science students. 
In week 3 (out of 15 course weeks), students had each to submit a complex data set they desired to visualize as their semester project. They were asked to describe the data in a conceptual form (something they learned to do in the previous lecture), set visualization goals, suggest visualization techniques, and describe possible users. This, we hoped, would bring out the topics that the students personally cared about. The received project proposition brought to light many individual interests (e.g. visualization of 20.000 auctions from the on-line game World-of-Warcraft; visualization of web search results or of traffic analyses) but also of some "hot spots", e.g. visualization of medical, weather or ecological data. In a group effort between all tutors, 7 projects that seemed representative (and interesting) of the 48 data sets were selected: visualizing orthopaedic data on human striding styles utilizing a game engine; visualizing indicators of the very large OECD education data base; visualizing data of the European pollutant emission register; visualizing data of over 70 runs of one student in preparation for a marathon; network performance visualization; flow visualization of a hurricane; and medical volume visualization.

Supporting the team building process: The lecture time of 1.5 hours in week 4 was fully devoted to the team building process around these 7 projects. It was a requirement that students built teams by selecting team members from all three faculties. This ensured a distribution of similar core curriculum knowledge in each team. Students who had submitted the selected 7 projects where allowed to start the team building process. Support for the selection process was also provided through the "private profiles" collected from all students. Students sometimes declined their selection, if they wanted to be picked by another group. Such a declination was accepted, as the goal was to form groups that liked to work together and found interest in the niche topic at hand.

To help students in starting up the communication process in their group, the assignment for the first group meeting included a brainstorming session on the group project. This brainstorming session was a guided role play that made sure that each of the students had a communicative role in the discussion process. This assignment intended to dampen unrealistic expectations of team members, let everyone voice their understanding of the joint project and "break the ice" in their communication. After the first meeting, each team had to meet at least once a week and keep meeting notes using a strict protocol. Meeting notes were also sent to tutors and instructor. Team members present, action items for the week to come, and the date of the next meetings were obligatory items in the notes. Instructor or tutors would show up at the meetings without notice - both to help on the content of the project and with interpersonal problems, should any arise.

Qualitative and quantitative assessment of course: Admittedly, not everyone of the 48 students found the topic with their personal strongest passion because, in order to build teams with different disciplines involved, we reduced the amount of projects from 48 to 7 . However, there were always several team members on each team that did feel passionate about the project goals. In all cases but one the team members became personal friends, sometimes even to the point that they would alter personal characteristics as in the case of the "Jogging Group": One runner had suggested providing data tracking over 70 of his runs via cell phone and tracker software, including running length, speed, altitude, temperature, etc. All members of the project group became runners (and very good friends) by the time the project ended. Only in one 
project (out of seven) the group worked incoherently, splitting into two groups, separating not disciplines but cultures.

A voluntary assessment of students reveals more about the course. Of 48 students, 30 students returned the survey: 18 computer science students; 9 business information systems students; and 3 non-technical students (two media science students and one literature student).

The survey revealed that only $33 \%$ of the students had previously participated in interdisciplinary (or transdisciplinary) courses at their university, $67 \%$ had not. The percentage of computer science students with experience in interdisciplinarity was lower than the average experience in this group. The desire of all students to later work in interdisciplinary teams was up at $90 \%$.

Students were also asked what they would like to know about each other before teaming up in a project group: they showed a strong preference (53\%) for "the abilities this person brings to the project" rather than "private information" $(10 \%)$ or "project interest" (4\%).

The number of actual face-to-face meetings for each team was one per week during the first weeks (the obligatory group meeting they had to report about) and 2, 3, or more meetings per week between week 9 and 15. Students used cell phones, Email, ICQ, SVN (a version control system), Wiki, and Skype to communicate between meetings.

The "private profiles" were used by $67 \%$ of the students to look up private information of course mates. Business information system and non-technical students used it to a higher percentage than computer science students.

After the project presentations, each student was asked to fill out an additional survey. In one of those questions the percentage of contribution to the project of each individual team member was requested. The closer knit the group had become, the closer these numbers matched. We found perfect matches in all numbers for the "jogging group", closely matching numbers in five other groups, but widely differing numbers in the culturally split group described earlier in this section.

\section{Implications and Future Opportunities}

Our educational objectives are grounded in the need for competencies in transdisciplinary collaboration to cope with the complexity of real-world problems. Our credo for transdisciplinary collaboration and lifelong learning argues that we must provide students with educational experiences to prepare them for this world. Many educational programs in computer science are still dominated by curriculum-driven learning (where the teachers set the goals and determine the content) rather than providing students with the opportunity to become reflective professionals allowing them to acquire the capacity for life-long learning and respect and ability to work with the perspectives of many, formerly separate disciplines. For the $21^{\text {st }}$ century, educational experiences need to be focused on how to improvise, innovate, and learn when the answer is not known, and how to make all voices heard. This is especially important at a time where many high level objectives in education are focused on a climate for test taking, bookkeeping, and cutting expenses - the wrong strategies as economic competition heats up around the globe and societies are exploring new ways to make 
their individual members more creative, imaginative, and innovative. The authors are convinced that the competency of transdisciplinary collaboration and self-directed learning, awakened in our students, will support a new climate of problem solving in this century.

\section{Acknowledgement}

Both authors thank the members of the Center for LifeLong Learning \& Design (L3D) at the University of Colorado at Boulder for providing background information and inspiring debates about the content of this paper. Gerhard Fischer's ideas and understanding about transdisciplinary collaboration and education have greatly benefited from collaboration with Sharon Derry (University of Wisconsin) and David Redmiles (University of California at Irvine). Gitta Domik thanks Ingrid and Stefanie Fischer for providing loving support to her son during her sabbatical at L3D.

\section{References}

1. Friedman, T.L.: The World is Flat: A brief history of the twenty-first century. Farrar, Straus and Giroux, New York (2005)

2. Aspray, W., Mayadas, F., Vardi, M.Y.: Globalization and Offshoring of Software - A Report of the ACM Job Migration Task Force (2006), http://www1.acm.org/ globalizationreport/

3. Drucker, P.F.: The Age of Social Transformation. The Atlantic Monthly, 53-80 (November 1994)

4. Derry, S., Fischer, G.: Toward a Model and Theory for Transdisciplinary Graduate Education. Paper Presented at 2005 AERA Annual Meeting, Symposium, Sociotechnical Design for Lifelong Learning: A Crucial Role for Graduate Education, Montreal (April 2005), http://13d.cs.colorado.edu/gerhard/papers/aera-montreal.pdf (2005)

5. Klein, J.T.: A Platform for a Shared Discourse of Interdisciplinary Education. Journal of Social Science Education 5(2), 10-18 (2006), http: / / www . jsse. org

6. Rosenfield, P.L.: The potential of transdisciplinary research for sustaining and extending likages between the health and social sciences. Social Sciences and Medicine 35, 1343 1357 (1992)

7. Nicolescu, B.: The transdisciplinary evolution of learning (1999), http: / /www. unesco.org/education/educprog/lwf/dl/ nicolescu_f.pdf

8. Norman, D.A.: In defense of cheating (Electronic Version). From: Ubiquity 6(11) (2005), http://www.acm.org/ubiquity/views/v6i11_norman.html

9. Stokols, D.: Towards a Science of Transdisciplinary Action Research. American Journal of Community Psychology 38, 63-77 (2006)

10. Computing Curricula (2001), http://www.computer-org-portal-cms_docs_ieeecs-ieeecseducation-cc2001-cc2001.pdf

11. Rushmeier, H.: IEEE Workshop on Visualization Education for Non-Technical Majors: Post Workshop Materials (2006), http://graphics.cs.yale.edu/holly/ vis2006/vis-non-tech.html 
12. Domik, G., Goetz, F.: A Breadth-First Approach for Teaching Computer Graphics. Education Papers. In: Proceedings of Eurographics 2006, Vienna, Austria, September 4-8, pp. 15 (2006)

13. Anderson, C.: The Long Tail: Why the Future of Business is Selling Less of More. Publisher Hyperion 2006 (2006), ISBN 1401302378

14. Brown, J.S., Adler, R.P.: Minds on Fire: Open Education, the Long Tail, and Learning 2.0 (2008), http: / /www. educause.edu/ir/library/pdf /ERM0811.pdf

15. Fischer, G.: Cultures of Participation and Social Computing: Rethinking and Reinventing Learning and Education. In: Proceedings of the International Conference on Advanced Learning Technologies (ICALT), pp. 1-5. IEEE Press, Riga (2009)

16. Benkler, Y.: The Wealth of Networks: How Social Production Transforms Markets and Freedom. Yale University Press, New Haven (2006)

17. National-Research-Council: Beyond Productivity: Information Technology, Innovation, and Creativity. National Academy Press, Washington (2003)

18. Collins, A., Fischer, G., Barron, B., Liu, C., Spada, H.: Long-Tail Learning: A Unique Opportunity for CSCL? In: Proceedings of CSCL 2009: 8th International Conference on Computer Supported Collaborative Learning, vol. 2, pp. 22-24. University of the Aegean, Rhodes (2009)

19. Domik, G.: Do We Need Formal Education in Visualization? Visualization Viewpoint. IEEE Computer Graphics and Applications 20(4) (2000)

20. Mackinlay, J.: Automating the Design of Graphical Presentations of Relational Information. ACM Trans. on Graphics 5(2), 110-141 (1986) 